\title{
Lateral Response Comparison of Unbonded Elastomeric Bearings Reinforced with Carbon Fiber Mesh and Steel
}

\author{
Ali Karimzadeh Naghshineh, Ugurhan Akyuz, and Alp Caner \\ Department of Civil Engineering, Middle East Technical University, Universiteler Mahallesi, \\ Dumlupinar Bulvari No. 1, Cankaya, 06800 Ankara, Turkey \\ Correspondence should be addressed to Ali Karimzadeh Naghshineh; ali_naghshine@yahoo.com
}

Received 12 November 2014; Revised 10 December 2014; Accepted 25 December 2014

Academic Editor: Mohammad Elahinia

Copyright (C) 2015 Ali Karimzadeh Naghshineh et al. This is an open access article distributed under the Creative Commons Attribution License, which permits unrestricted use, distribution, and reproduction in any medium, provided the original work is properly cited.

\begin{abstract}
The vertical and horizontal stiffness used in design of bearings have been established in the last few decades. At the meantime, applicability of the theoretical approach developed to estimate vertical stiffness of the fiber-reinforced bearings has been verified in different academic studies. The suitability of conventional horizontal stiffness equation developed for elastomeric material, mainly for steel-reinforced elastomeric bearings, has not been tested in detail for use of fiber-reinforced elastomeric bearings. In this research, lateral response of fiber mesh-reinforced elastomeric bearings has been determined through experimental tests and the results have been compared by corresponding values pertaining to the steel-reinforced bearings. Within the test program, eight pairs of fiber mesh-reinforced bearings and eight pairs of steel-reinforced bearings are subjected to different levels of compressive stress and cyclic shear strains. Fiber-reinforced elastomeric bearings may be more favorable to be used in seismic regions due to lower horizontal stiffness that can result in mitigation of seismic forces for levels of $100 \%$ shear strain. Damping properties of these types of fiber mesh-reinforced bearings depend mostly on the selection of elastomeric material compounds. Suggestions have been made for the lateral response of fiber-reinforced elastomeric bearings. It has also been determined that the classical equation for lateral stiffness based on linear elastic behavior assumptions developed for elastomeric bearings does not always apply to the fiber-reinforced ones.
\end{abstract}

\section{Introduction}

Fiber mesh-reinforced elastomeric bearings are becoming popular in the academic researches. Most of the design equations used for fiber mesh-reinforced bearings are adapted from the known elastomeric material behavior or mainly the ones developed for the steel-reinforced elastomeric bearings. Lack of a complete lateral response comparison between full size fiber-reinforced and steel-reinforced bearings and limited amount of research on lateral structural response of fiber-reinforced bearings in the known literature are the main reasons to conduct this research.

Elastomeric bearings reinforced by steel plates are the most common types of the bearings used for seismic isolation or standard bearings of the structures. In an attempt to decrease the weight and cost of these bearings, Kelly [1] introduced a certain type of fiber-reinforced elastomeric bearings and showed that these bearings can provide adequate vertical stiffness for base isolation.

Fiber-reinforced elastomeric bearings were studied by many researchers during the past decades. Moon et al. [2] manufactured fiber-reinforced elastomeric bearings using different types of fiber reinforcement. They compared the performance of these bearings and concluded that carbon fiber-reinforced bearings have superior performance parameters. Ashkezari et al. [3] manufactured some specimens of multilayer elastomeric seismic isolators reinforced by layers of woven carbon and steel. They concluded that "steel like fiber-reinforced elastomeric isolators" (SLFREI) can be used in seismic isolation of structures. Compared to others, Toopchi-Nezhad et al. $[4,5]$ studied the lateral response of fiber-reinforced bearings using shake table testing method. Zhang et al. [6] studied the mechanical properties of FRPbased elastomeric isolators after manufacturing and testing 
TABle 1: Properties of steel-reinforced and fiber-reinforced bearings.

\begin{tabular}{|c|c|c|c|c|c|c|c|c|c|c|c|}
\hline Type & $\begin{array}{c}a \\
(\mathrm{~mm})\end{array}$ & $\begin{array}{c}b \\
(\mathrm{~mm})\end{array}$ & $\begin{array}{c}R \\
(\mathrm{~mm})\end{array}$ & $\begin{array}{c}t_{c} \\
(\mathrm{~mm})\end{array}$ & $\begin{array}{c}t_{r} \\
(\mathrm{~mm})\end{array}$ & $\begin{array}{l}t_{\text {sor } f} \\
(\mathrm{~mm})\end{array}$ & $n_{r}$ & $n_{s}$ & $\begin{array}{c}T_{r} \\
(\mathrm{~mm})\end{array}$ & $H$ & $\begin{array}{l}\text { Shape } \\
\text { factor }\end{array}$ \\
\hline S1y & 250 & 400 & * & 5 & 8 & 2.0 & 7 & 6 & 50 & 62.00 & 9.28 \\
\hline$F 1 y$ & 250 & 400 & $*$ & 5 & 8 & 0.125 & 7 & 6 & 50 & 50.75 & 9.28 \\
\hline$S 1 z$ & 250 & 400 & $*$ & $*$ & 5 & 2.0 & 7 & 6 & 35 & 47.00 & 14.85 \\
\hline$F 1 z$ & 250 & 400 & $*$ & $*$ & 5 & 0.125 & 7 & 6 & 35 & 35.75 & 14.85 \\
\hline$S 2 y$ & 300 & 300 & $*$ & 5 & 6 & 2.0 & 7 & 6 & 40 & 52.00 & 12.08 \\
\hline$F 2 y$ & 300 & 300 & $*$ & 5 & 6 & 0.125 & 7 & 6 & 40 & 40.75 & 12.08 \\
\hline$S 2 z$ & 300 & 300 & $*$ & * & 5 & 2.0 & 7 & 6 & 35 & 47.00 & 14.50 \\
\hline$F 2 z$ & 300 & 300 & $*$ & * & 5 & 0.125 & 7 & 6 & 35 & 35.75 & 14.50 \\
\hline S3y & $*$ & * & 100 & $*$ & 10 & 2.0 & 4 & 3 & 40 & 46.00 & 4.75 \\
\hline$F 3 y$ & $*$ & * & 100 & $*$ & 10 & 0.125 & 4 & 3 & 40 & 40.38 & 4.75 \\
\hline$S 3 z$ & $*$ & * & 100 & $*$ & 5 & 2.0 & 10 & 9 & 50 & 68.00 & 9.50 \\
\hline$F 3 z$ & * & $*$ & 100 & * & 5 & 0.125 & 10 & 9 & 50 & 51.13 & 9.50 \\
\hline S4y & 150 & 150 & $*$ & $*$ & 4 & 1.0 & 12 & 11 & 48 & 59.00 & 8.75 \\
\hline$F 4 y$ & 150 & 150 & $*$ & * & 4 & 0.125 & 12 & 11 & 48 & 49.38 & 8.75 \\
\hline$S 4 z$ & 150 & 150 & $*$ & $*$ & 2 & 1.0 & 20 & 19 & 40 & 59.00 & 17.50 \\
\hline$F 4 z$ & 150 & 150 & * & * & 2 & 0.125 & 20 & 19 & 40 & 42.38 & 17.50 \\
\hline
\end{tabular}

${ }^{*}$ Not applicable.

a number of samples. Calabrese and Kelly [7] reviewed the response of fiber-reinforced bearings and compared the results of finite element analysis with the proposed theoretical approach. Russo et al. [8] studied the shear behavior of fiberreinforced elastomeric bearings and they proposed a new expression for the horizontal stiffness of the fiber-reinforced bearings. They studied the deformed configuration of fiberreinforced bearings under shear strains. Hedayati Dezfuli and Alam [9] probed the effect of physical and mechanical properties such as thickness and shear modulus of rubber layers on the performance of the FREIs in bonded applications. Karimzadeh Naghshineh et al. [10] compared the fundamental properties of fiber mesh-reinforced isolators with the conventional steel-reinforced isolators. ToopchiNezhad [11] presented two simplified analytical models for horizontal stiffness evaluation of unbonded fiber-reinforced elastomeric bearings.

Carbon fiber mesh with opening described in the study by Karimzadeh Naghshineh et al. [10] was used in this research and details of the reinforcing materials can be found in the study by Karimzadeh Naghshineh et al. [10]. Effects of fiber flexibility on vertical stiffness of the bearings have been studied by Kelly and Takhirov [12]. In previous researches, there is not any experimental study which compares the lateral stiffness of unbonded fiber- and steel-reinforced bearings. In this research, lateral response of fiber- and steel-reinforced bearings in unbonded application will be compared through investigating results of experimental program. To investigate the effect of parameters such as geometry and size on lateral response of fibe-reinforced bearings, eight pairs of fiber-reinforced bearings with different properties are manufactured. Steel-reinforced bearings are manufactured with the same geometric and elastomeric properties used for fiberreinforced bearings. Under these conditions, a comprehensive comparison between fiber- and steel-reinforced bearings has been made. For verification purposes, suggestions for the lateral response of fiber-reinforced bearings have been made.

It shall be noted that fiber mesh-reinforced elastomeric bearings are typically manufactured using "cold" manufacturing technique that involves applying bonding agents between layers of fiber mesh and rubber. To eliminate use of bonding agent between elastomeric materials and reinforcing material, vulcanization through high temperatures is selected as the manufacturing process that has also been used in the typical manufacturing method for steel-reinforced bearings. This type of manufacturing process was also used by Russo and Pauletta [13].

\section{Materials and Methods}

2.1. Test Specimens. Several samples of fiber- and steelreinforced bearings were manufactured. In manufacturing all of these bearings, high damping natural rubber with the nominal stiffness of 60 Shore $A$ was used. The nominal shear modulus of rubber material was $0.7 \mathrm{MPa} \pm 0.15 \mathrm{MPa}$ and the effective damping of rubber compound was around $8 \%$. Geometrical properties of all bearings were presented in Table 1. In Table 1, the type is denoted by three characters in which the first character displays the reinforcement type ( $F$ for fiber and $S$ for steel), the second character shows the specimen number $(1,2,3$, or 4$)$, and the third character indicates the shape factor of specimen ( $z$ represents a higher shape factor compared to $y$ ). In the second and third columns, $a$ is used for width 


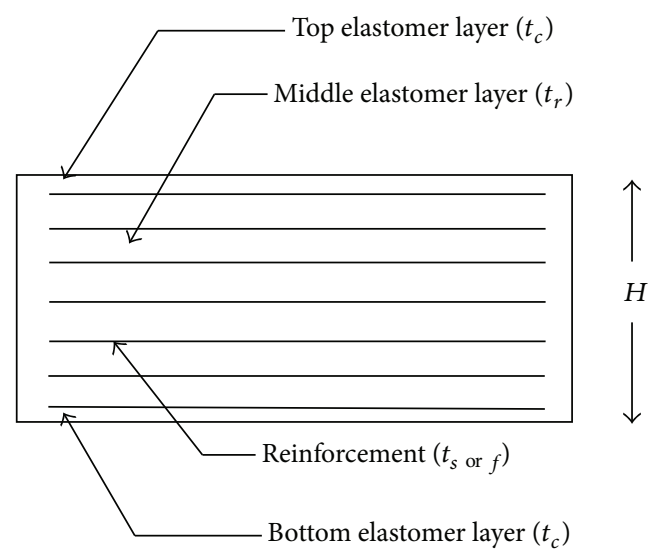

FIGURE 1: Schematic view of bearing parameters.

of the bearing and $b$ is used for the length of the bearing. In the fourth column, $R$ shows radius of circular bearings; in the fifth column, $t_{c}$ is the thickness of top and bottom cover layers. In the sixth column, $t_{r}$ is the thickness of middle elastomer layers. In the seventh column, $t_{\text {sor } f}$ is the thickness of reinforcing steel plates or fiber reinforcement. In the eighth column, $n_{r}$ is number of elastomer layers with considering the top and bottom cover layers. In the ninth column, $n_{s}$ is the number of reinforcing layers. In the tenth column, $T_{r}$ is the total thickness of elastomer layers. In the eleventh column, $H$ is the total thickness of bearing with considering the reinforcement thickness. Shape factor of bearing is usually defined as the ratio of loaded area to force-free area. Figure 1 illustrates the bearings parameters in schematic manner.

\subsection{Horizontal Shear Stiffness Test Setup. Seismic isolator} testing system available in Structure Engineering Laboratory of Middle East Technical University has been designed to test the isolators in horizontal direction under constant vertical load. This system is capable of conducting in-plane horizontal cyclic loading tests, as shown in Figures 2(a) and 2(b). This machine can test a pair of elastomeric bearings by applying vertical pressure and keeping it constant at a desired level and then implementing cyclic displacement control loading in horizontal direction. Load capacity of testing system is about $3000 \mathrm{kN}$ in vertical direction and this value reduces to $600 \mathrm{kN}$ for horizontal direction.

Test setup is composed of two distinct main loading systems in horizontal and vertical directions; loading system in vertical direction is used for applying the desired level of pressure and loading system in horizontal direction is capable of controlling the applied displacement. Loading system in vertical direction with its adjustable upper plate provides testing opportunity for different type and size of bearings. Horizontal loading system is capable of sliding on rails located on vertical support plates to adjust the inserted horizontal load in accordance with the bearing's height. Also, horizontal loading system can be relocated on bottom support plates to increase the horizontal loading capacity. Two linear variable differential transformers (LVDT) placed on middle sliding plate were used to measure the horizontal displacement of the bearing during shear test. Data acquisition system was run by a PC Windows-based control and acquisition program called StrainSmart 6000 developed by Vishay Precision Group, Wendell, USA. System 6000 features data acquisition rates of up to 10,000 samples per second per channel. It is worth noting that the average sampling rate was 100 per second in all of the tests.

2.3. Test Procedure. Bearings were tested under horizontal displacement control during the horizontal test. Bearings were subjected to shear in pairs under a vertical load equivalent to a pressure of 6.90 and $3.45 \mathrm{MPa}$. The selected compressive pressures are typical design pressures for this type of bearings. They were tested in cyclic shear, with three fully reversed cycles at three maximum strain levels of $25 \%$, $50 \%$, and $100 \%$ based on the total rubber thickness. Horizontal stiffness of the bearings and their equivalent viscous damping ratio were calculated by analyzing the hysteresis loops obtained during this test.

The loading history of the horizontal test for bearings is presented in Figure 3 and this figure depicts the input signal for specimens. Different seismic isolation systems have also been tested at the Middle East Technical University by Pinarbasi et al. [14], Ozkaya et al. [15], and Caner et al. [16].

Loading history of bearings affects the response of the bearings in such a way that, during the first several cycles, the bearing has higher effective horizontal stiffness and damping (scragging effect). By the third cycle, the response of the bearing has stabilized and the responses presented in this study are stabilized response of bearing.

\subsection{Investigated Test Parameters for Elastomeric Bearings.} Results of horizontal shear test were used to calculate the horizontal stiffness of the bearings. A simple calculation of shear stiffness based on the values of peak force and displacement is defined as

$$
K_{\mathrm{eff}}^{h}=\frac{\left|F^{+}\right|+\left|F^{-}\right|}{\left|d^{+}\right|+\left|d^{-}\right|},
$$

where $d^{+}$and $d^{-}$are the maximum positive and maximum negative test displacements, respectively, and $F^{+}$and $F^{-}$are the forces at instance of displacements $d^{+}$and $d^{-}$, respectively [17]. This stiffness is interpreted as the effective or overall stiffness of the bearing during the test. This stiffness is used to calculate the stored or elastic energy of the bearings during cyclic tests.

The hysteresis loops were also analyzed to obtain the equivalent viscous damping ratio of the bearing for each test. A hysteresis loop represents the plot of force against displacement, and, therefore, the area contained within such a loop represents the energy dissipated by the bearing.

The equivalent viscous damping ratio exhibited by the bearing is evaluated in the usual structural engineering fashion [18]:

$$
\xi=\frac{W_{d}}{4 \pi W_{s}},
$$




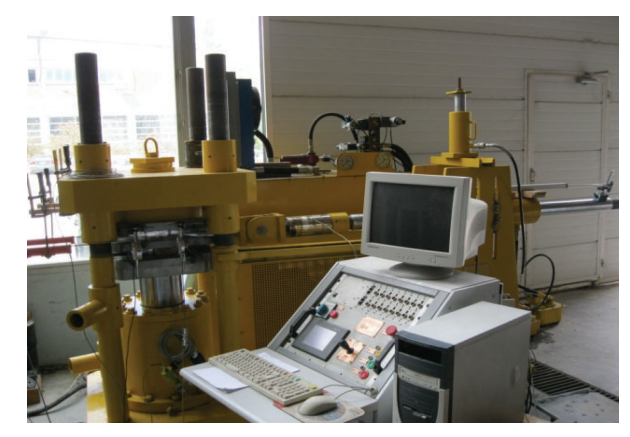

(a) Testing system

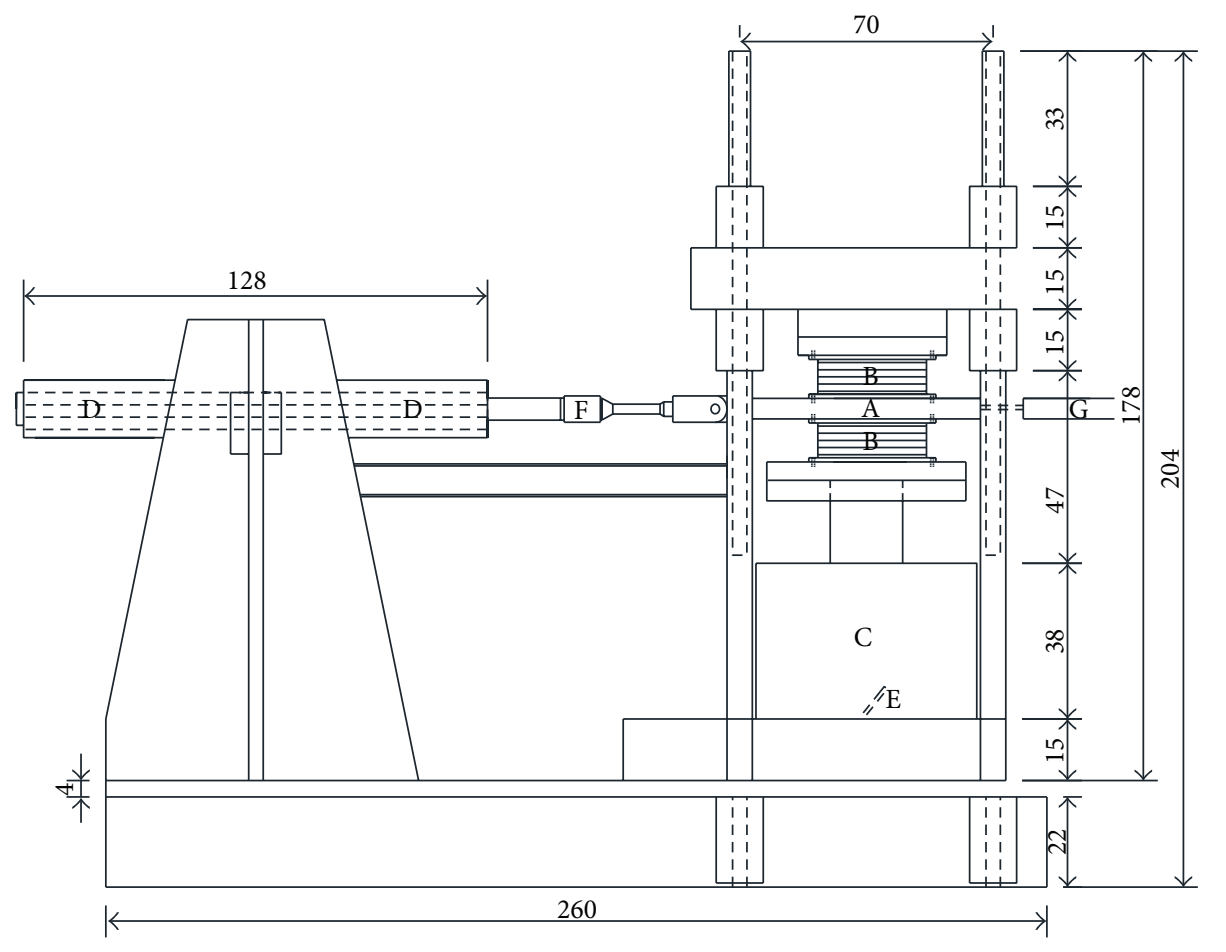
(A) Push-pull steel plate
(E) Load cell in the vertical direction
(B) Bearings to be tested (two bearings are tested)
(F) Load cell in the horizontal direction
(C) Hydraulic cylinder (for application of vertical loads)
(G) LVDT
(D) Hydraulic cylinder (for application of horizontal loads)

(b) Schematic layout (dimensions: $\mathrm{cm}$ )

FIGURE 2: General view of the horizontal shear test equipment.

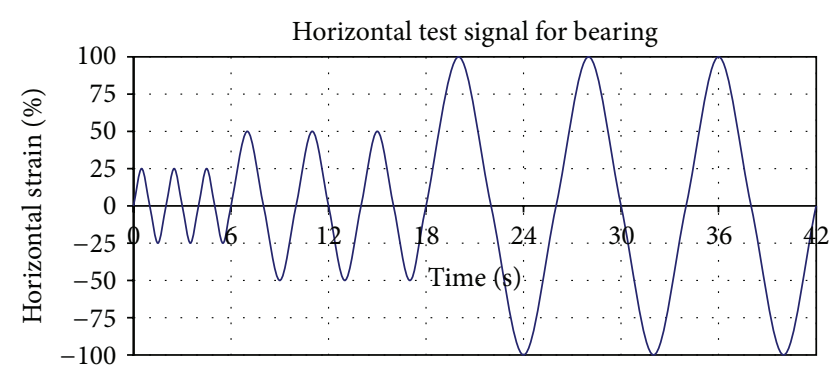

FIGURE 3: Input signal for horizontal shear test with $3.45 \mathrm{MPa}$ and 6.90 MPa vertical preload. where $W_{d}$ represents a dissipated energy equal to the hysteresis loop area and $W_{s}$ corresponds to stored or elastic energy defined by the following formula:

$$
W_{s}=K_{\mathrm{eff}}^{h} \frac{d_{\max }^{2}}{2} .
$$

Here, $d_{\max }$ is the average of positive and negative maximum displacements and is defined as

$$
d_{\max }=\frac{\left|d^{+}\right|+\left|d^{-}\right|}{2} .
$$


TABLE 2: Equivalent viscous damping values.

\begin{tabular}{|c|c|c|c|c|c|c|c|c|}
\hline \multirow{4}{*}{ Type and damp ratio } & \multicolumn{8}{|c|}{ Equivalent viscous damping, $\xi \%$ under vertical pressure ( $\mathrm{MPa}$ ) } \\
\hline & \multicolumn{4}{|c|}{3.45} & \multicolumn{4}{|c|}{6.90} \\
\hline & \multicolumn{4}{|c|}{ Strain level (\%) } & \multicolumn{4}{|c|}{ Strain level (\%) } \\
\hline & 25 & 50 & 100 & Average & 25 & 50 & 100 & Average \\
\hline S1y & 11.6 & 10.8 & 13.6 & 12 & 8.6 & 10 & 9.6 & 9.4 \\
\hline$F 1 y$ & 10.7 & 10.7 & 10.9 & 10.8 & 7.5 & 8.2 & 9.8 & 8.5 \\
\hline$\xi_{s} / \xi_{f}$ & 1.09 & 1.01 & 1.25 & 1.11 & 1.15 & 1.23 & 0.98 & 1.11 \\
\hline$S 1 z$ & 10.2 & 13.2 & 12.5 & 11.97 & 6.7 & 9.2 & 10.9 & 8.93 \\
\hline$F 1 z$ & 13.4 & 16.6 & 15.0 & 15.0 & 7.4 & 12.1 & 13.2 & 10.9 \\
\hline$\xi_{s} / \xi_{f}$ & 0.76 & 0.79 & 0.83 & 0.80 & 0.91 & 0.76 & 0.83 & 0.82 \\
\hline$S 2 y$ & 8.4 & 11.6 & 13.2 & 11.07 & 5.8 & 8.8 & 8.7 & 7.7 \\
\hline$F 2 y$ & 11.7 & 10.1 & 8.7 & 10.2 & 6.5 & 10.9 & 7.9 & 8.4 \\
\hline$\xi_{s} / \xi_{f}$ & 0.72 & 1.15 & 1.51 & 1.09 & 0.90 & 0.81 & 1.09 & 0.92 \\
\hline$S 2 z$ & 7.4 & 11.3 & 14.3 & 11.0 & 5.3 & 7.8 & 12.4 & 8.5 \\
\hline$F 2 z$ & 9.4 & 10.4 & 8.9 & 9.6 & 6 & 9.1 & 7.6 & 7.6 \\
\hline$\xi_{s} / \xi_{f}$ & 0.79 & 1.09 & 1.59 & 1.15 & 0.88 & 0.86 & 1.62 & 1.12 \\
\hline S3y & 5.8 & 8.5 & 10.2 & 8.2 & 5.2 & 6.3 & 7.8 & 6.4 \\
\hline$F 3 y$ & 6.9 & 8.5 & 9.2 & 8.2 & 5 & 5.8 & 7.2 & 6.0 \\
\hline$\xi_{s} / \xi_{f}$ & 0.84 & 1.00 & 1.11 & 1.00 & 1.04 & 1.09 & 1.09 & 1.07 \\
\hline$S 3 z$ & 8.5 & 6.9 & 7.7 & 7.7 & 5.1 & 5 & 6.3 & 5.5 \\
\hline$F 3 z$ & 6 & 7.8 & 8 & 7.3 & 5.7 & 5.5 & 7.5 & 6.2 \\
\hline$\xi_{s} / \xi_{f}$ & 1.42 & 0.89 & 0.97 & 1.06 & 0.88 & 0.90 & 0.84 & 0.88 \\
\hline S4y & 10.1 & 11.4 & 10.5 & 10.7 & 9.9 & 8.8 & 9.9 & 9.5 \\
\hline$F 4 y$ & 9.8 & 9.3 & 8.4 & 9.2 & 9.8 & 8.6 & 8 & 8.8 \\
\hline$\xi_{s} / \xi_{f}$ & 1.03 & 1.23 & 1.26 & 1.16 & 1.01 & 1.02 & 1.23 & 1.08 \\
\hline$S 4 z$ & 9.7 & 10.3 & 8.8 & 9.6 & 9.7 & 8.1 & 9.5 & 9.1 \\
\hline$F 4 z$ & 10.8 & 10.1 & 9.7 & 10.2 & 10 & 8.7 & 8.4 & 9.0 \\
\hline$\xi_{s} / \xi_{f}$ & 0.90 & 1.02 & 0.91 & 0.94 & 0.98 & 0.93 & 1.14 & 1.01 \\
\hline
\end{tabular}

The linear viscous model assumes that the energy dissipated in each cycle is linear with the frequency and quadratic with the displacement [18].

Dynamic response of an isolated structure depends mainly on the horizontal stiffness of isolators. The following equation for horizontal stiffness, $K_{h}$, is based on the simple analysis that can be found in strength of material text books and is used for both steel and fiber reinforcement conditions, although the equation is developed for elastomeric materials:

$$
K_{h}=\frac{A G}{T_{r}},
$$

where $K_{h}$ is horizontal stiffness of bearing $(\mathrm{kN} / \mathrm{m}), G$ is shear modulus of elastomer (MPa), $T_{r}$ is total thickness of elastomeric material ( $\mathrm{mm})$, and $A$ is plan area of the bearing $\left(\mathrm{mm}^{2}\right)$.

\section{Test Results and Discussion}

Results of horizontal shear test are presented in this part. In Table 2, a comparison of numerical values of the damping of both types of bearings at different strain levels is presented. The average damping of the bearing is the arithmetic mean of the damping values during all the cycles. As it is clear from the presented results in Table 2, there is not that much of difference between the average values of damping pertaining to the fiber mesh- and steel-reinforced bearings. The maximum difference between the average damping ratios is about $20 \%$. The main source of energy dissipation in these elastomeric bearings is rubber compound and selection of reinforcement material is believed not to result in big difference in damping values. The damping values in this kind of fiber- and steel-reinforced bearing are within reasonable tolerances.

Horizontal effective stiffness test results of the bearings are presented in Table 3. The horizontal stiffness of the steel-reinforced bearings and that of fiber mesh-reinforced bearings do not differ much for large size bearings which had higher stiffness compared to the small sizes as expected. Larger specimens are more stable to rollover due to their geometrical properties and high ratios of area to elastomer thickness and rollover starts at high levels of shear strain in these bearings. 
The same observation cannot be made for the small size bearings due to the early rollover response of the fiber meshreinforced bearings that decreased the stiffness at larger strain values significantly as shown in Figures 4(a)-4(d). In all of the shear tests, as strain level increases, effective stiffness of bearings decreases. Increase in vertical preload resulted in higher values of horizontal stiffness.

For Type 1 bearings, large size ones, at lower strain levels (up to 50\%), stiffness of fiber-reinforced bearings was slightly greater than the steel-reinforced ones. As strain level increases, rollover of fiber-reinforced bearings commenced and this phenomenon led to a decrease in stiffness. In Type 2 bearings, stiffness of fiber-reinforced bearings at lower strain levels is greater than steel-reinforced ones but as rollover starts their stiffness decreases drastically. For Types 3 and 4 bearings, decrease in stiffness developed at lower strain levels. This observation could be attributed to the small size of the bearings because rollover deformation is affected by the ratio between the bearing thickness and base side length and bearings with smaller ratios have more potential to develop rollover response than larger specimens. In larger specimens, rollover starts at larger levels of strain compared to small size bearings. In steel-reinforced bearings, the same observation of rollover happens at larger strain levels compared to fiberreinforced bearings. The governing trend in the tested specimens is that as strain level increases the difference between the effective stiffness of the steel-reinforced bearings and that of fiber-reinforced bearings increases and the amount of increase depends on several parameters such as size and vertical pressure.

The minimum divergence in stiffness of $1 \%$ is observed at high compressive stress levels for the bearings with larger plan area and thicker total elastomeric layers. The maximum divergence in stiffness of $78 \%$ is observed at low compressive stress levels for the small size bearing with lower total thickness of elastomeric materials.

The conventional horizontal stiffness presented in (5) has two components, one being material property and the other being size. The material property is presented by shear modulus $G$ and the size index is presented by $A / T_{r}$ ratio. In all the tests, the shear modulus $G$ is the same. Therefore, a relationship for size effect versus correction factor is developed within this research. The nonlinear relationship between horizontal stiffness of steel-reinforced bearings and that of fiber mesh-reinforced bearings can be represented by

$$
\frac{K_{(\mathrm{eff}) s}}{K_{(\mathrm{eff}) f}}=f\left(\frac{A}{T_{r}}\right)=\alpha,
$$

where $K_{(\mathrm{eff}) s}$ is horizontal effective stiffness of steel-reinforced bearings, $K_{(\mathrm{eff})} f$ is horizontal effective stiffness of fiber meshreinforced bearings, and $\alpha$ is nonlinear correction factor for size effect.

It has been experimentally determined that the $\alpha$ factor can be obtained from best fit curve using Figure 5:

$$
\alpha=6.09\left(\frac{A}{T_{r}}\right)^{-0.23} .
$$

Therefore, the effective horizontal stiffness of fiber meshreinforced bearings can be recommended for $100 \%$ strain:

$$
K_{(\mathrm{eff})}=\frac{G}{6.09}\left(\frac{A}{T_{r}}\right)^{1.23}, \quad \frac{A}{T_{r}} \leq 3000
$$

No correction is suggested for $A / T_{r}$ values exceeding $3000 \mathrm{~mm}^{2} / \mathrm{mm}$ and the effective stiffness for elastomeric material in (5) can be applied to fiber mesh-reinforced bearings. For strain levels less than $100 \%$, linear interpolation for the values given in Table 3 can be recommended to use.

The proposed equation does not take account of the particular rollover deformation of fiber-reinforced bearings, but as in the studies by Kelly [19, 20], for example, the expression for estimating the rollout stability limit changes by only 5 percent when the compression load is doubled. So this equation can be used to determine the horizontal stiffness of the fiber-reinforced bearings in the range of discussed pressures (3.45-6.90 MPa).

Unbonded small size fiber-reinforced bearings can develop very low horizontal stiffness compared to steelreinforced bearings and this may be considered as an advantage in design as long as rollover deformations of the bearings are stable. It shall be noted that the rollover did not develop any instability during tests. The reason is that all the specimens had curves with increasing resisting force at an increase of the applied shear deformation. No zero or negative tangent stiffness was observed in test results and after unloading there was not any residual deformation in the bearings. All the bearings sustained the applied load and strain levels and no visible damage was developed in bearings as shown in Figure 6.

It can be concluded that effective lateral stiffness of fiberreinforced bearings is affected by several parameters such as geometrical properties, strain level, and vertical preload. It can be stated that rollover response of fiber-reinforced bearing is beneficial if the bearing remains stable horizontally.

Hysteresis loops obtained in horizontal shear test for selected bearings are plotted in terms of horizontal displacement versus horizontal load as shown in Figures 7(a)-7(d). In this figure, horizontal axis corresponds to displacement of bearings ( $\mathrm{mm}$ ) and vertical axis corresponds to horizontal force $(\mathrm{kN})$. Horizontal stiffness for a single bearing is considered to be the half of the values since the tests are conducted simultaneously on two bearings.

\section{Conclusion}

Test results of new types of fiber mesh-reinforced elastomeric bearings and conventional isolators are compared. The observations made during the tests can be summarized as follows.

(i) The conventional horizontal stiffness used in design of elastomeric materials does not always apply to the fiber mesh-reinforced bearings. At high levels of shear strain, there is a significant deviation in horizontal stiffness of small size fiber mesh-reinforced bearings compared to steel-reinforced bearings. A nonlinear 


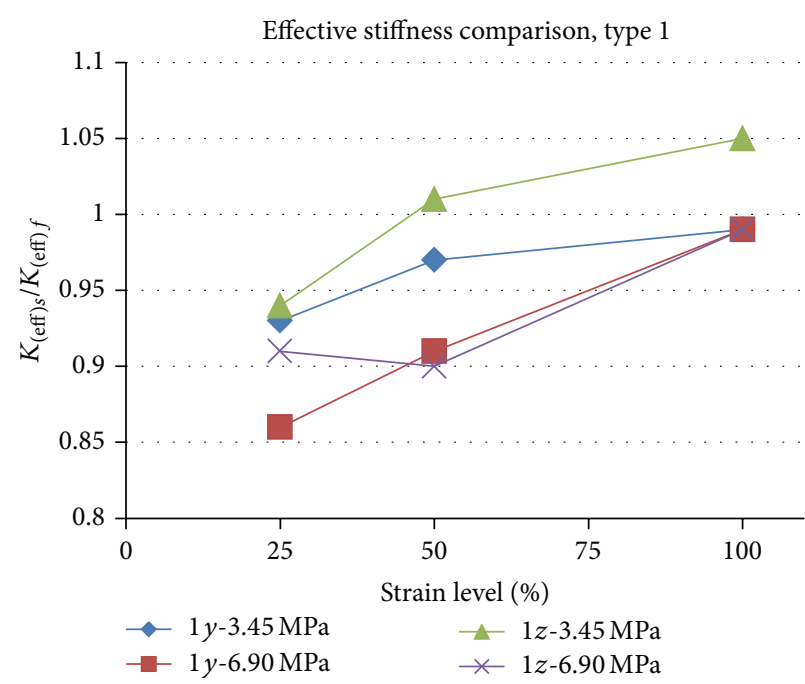

(a) Type 1 bearings: $\left(K_{\text {eff }}\right)_{s} /\left(K_{\text {eff }}\right)_{f}$ versus shear strain

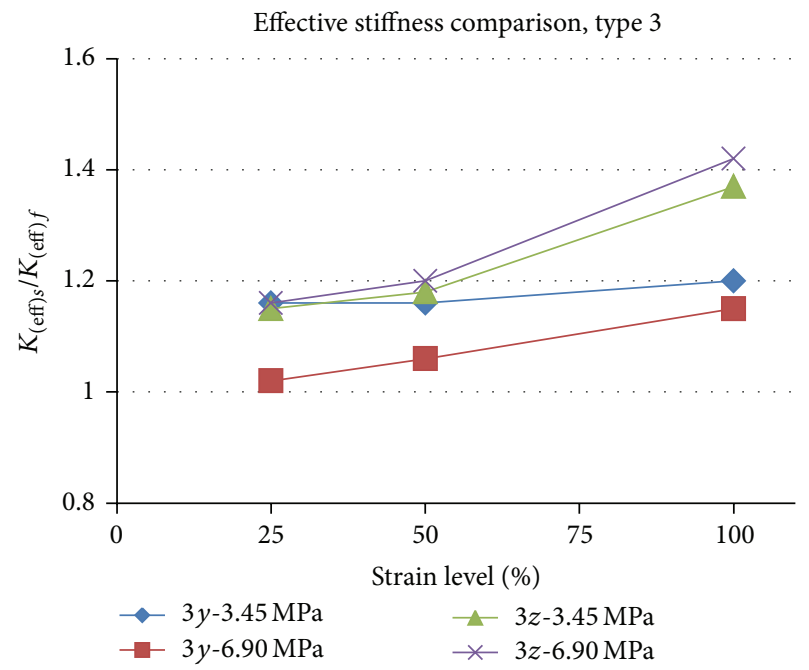

(c) Type 3 bearings: $\left(K_{\text {eff }}\right)_{s} /\left(K_{\text {eff }}\right)_{f}$ versus shear strain

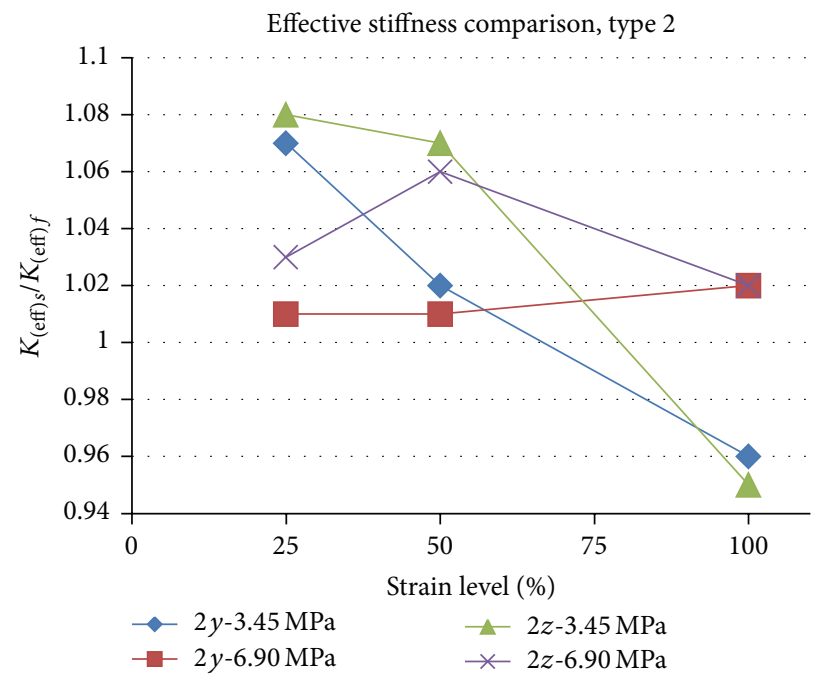

(b) Type 2 bearings: $\left(K_{\mathrm{eff}}\right)_{s} /\left(K_{\mathrm{eff}}\right)_{f}$ versus shear strain

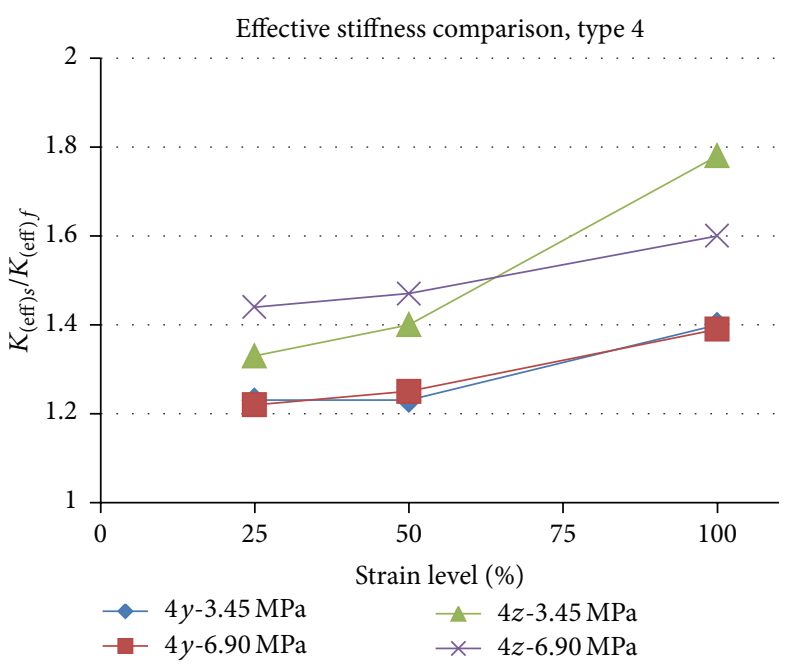

(d) Type 4 bearings: $\left(K_{\text {eff }}\right)_{s} /\left(K_{\text {eff }}\right)_{f}$ versus shear strain

FIGURE 4: Comparison of effective stiffness of steel-reinforced and fiber-reinforced bearings.

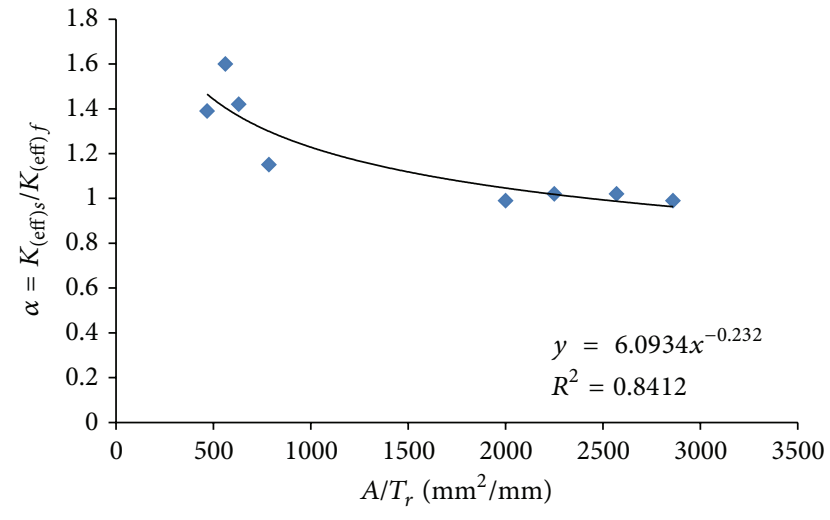

FIGURE 5: Suggested correction factor for horizontal stiffness for fiber mesh-reinforced bearings at 100\% strain level. equation is suggested as a correction factor for fiberreinforced bearing horizontal stiffness computations to account for this divergence.

(ii) The tests under different compressive loads revealed that the horizontal stiffness slightly increases under high compressive loads and proposed correction factor can be applied for both investigated cases in this research within a reasonable tolerance.

(iii) Damping values in both fiber- and steel-reinforced bearings are similar since the same elastomeric material is used in both reinforcement conditions. Damping is typically provided by the selection of elastomeric material. 


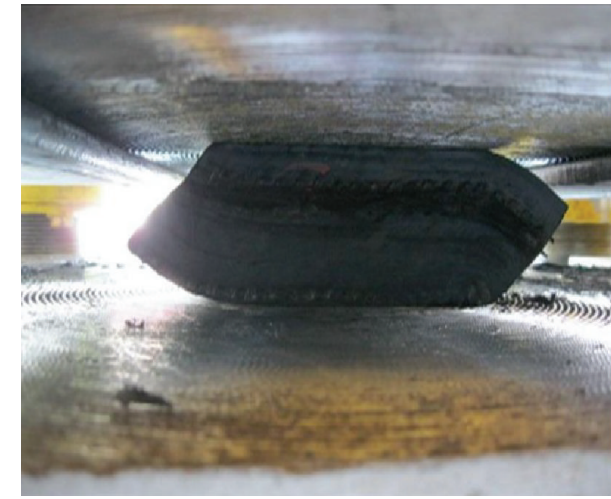

(a) Unbonded F4y at $100 \%$ strain

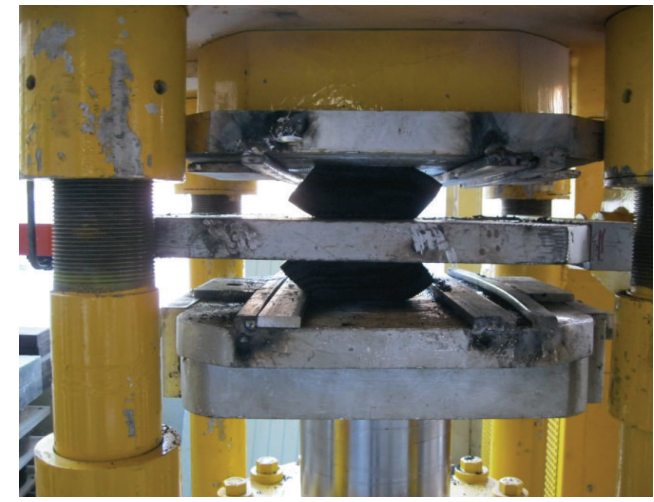

(b) Unbonded $54 y$ at $100 \%$ strain

FIGURE 6: Deformation mode shape of fiber mesh-reinforced bearings.

TABLE 3: Effective stiffness values.

\begin{tabular}{|c|c|c|c|c|c|c|}
\hline \multirow{4}{*}{ Type and stiffness ratio } & \multicolumn{6}{|c|}{$\begin{array}{c}\text { Effective stiffness } K_{\text {eff }}^{h}(\mathrm{kN} / \mathrm{m}) \\
\text { Vertical pressure }(\mathrm{MPa})\end{array}$} \\
\hline & \multirow{2}{*}{\multicolumn{3}{|c|}{$\begin{array}{c}3.45 \\
\text { Strain level (\%) }\end{array}$}} & \multirow{2}{*}{\multicolumn{3}{|c|}{$\begin{array}{c}6.90 \\
\text { Strain level (\%) }\end{array}$}} \\
\hline & & & & & & \\
\hline & 25 & 50 & 100 & 25 & 50 & 100 \\
\hline$S 1 y$ & 2221 & 1866 & 1619 & 2363 & 1995 & 1822 \\
\hline$F 1 y$ & 2383 & 1931 & 1633 & 2730 & 2187 & 1827 \\
\hline$K_{s} / K_{f}$ & 0.93 & 0.97 & 0.99 & 0.86 & 0.91 & 0.99 \\
\hline$S 1 z$ & 3438 & 2725 & 2387 & 3787 & 3005 & 2633 \\
\hline$F 1 z$ & 3674 & 2708 & 2278 & 4164 & 3326 & 2663 \\
\hline$K_{s} / K_{f}$ & 0.94 & 1.01 & 1.05 & 0.91 & 0.90 & 0.99 \\
\hline$S 2 y$ & 2519 & 2086 & 1784 & 2772 & 2307 & 2133 \\
\hline$F 2 y$ & 2347 & 2053 & 1865 & 2757 & 2296 & 2080 \\
\hline$K_{s} / K_{f}$ & 1.07 & 1.02 & 0.96 & 1.01 & 1.01 & 1.02 \\
\hline$S 2 z$ & 2962 & 2420 & 2035 & 3270 & 2755 & 2420 \\
\hline$F 2 z$ & 2737 & 2256 & 2135 & 3180 & 2602 & 2374 \\
\hline$K_{s} / K_{f}$ & 1.08 & 1.07 & 0.95 & 1.03 & 1.06 & 1.02 \\
\hline S3y & 944 & 762 & 657 & 918 & 793 & 707 \\
\hline$F 3 y$ & 811 & 656 & 548 & 898 & 751 & 617 \\
\hline$K_{s} / K_{f}$ & 1.16 & 1.16 & 1.20 & 1.02 & 1.06 & 1.15 \\
\hline$S 3 z$ & 669 & 559 & 507 & 716 & 609 & 562 \\
\hline$F 3 z$ & 582 & 472 & 371 & 615 & 508 & 395 \\
\hline$K_{s} / K_{f}$ & 1.15 & 1.18 & 1.37 & 1.16 & 1.20 & 1.42 \\
\hline S4y & 570 & 440 & 429 & 595 & 472 & 445 \\
\hline$F 4 y$ & 464 & 358 & 306 & 485 & 375 & 321 \\
\hline$K_{s} / K_{f}$ & 1.23 & 1.23 & 1.40 & 1.22 & 1.25 & 1.39 \\
\hline$S 4 z$ & 725 & 581 & 558 & 769 & 612 & 537 \\
\hline$F 4 z$ & 543 & 414 & 313 & 535 & 415 & 323 \\
\hline$K_{s} / K_{f}$ & 1.33 & 1.40 & 1.78 & 1.44 & 1.47 & 1.6 \\
\hline
\end{tabular}




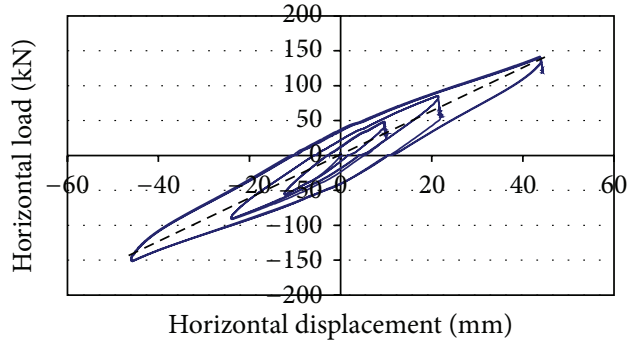

(a) F1 $y$ under 6.90 MPa vertical preload

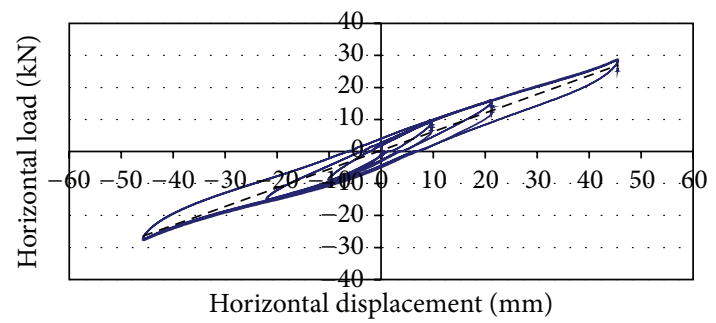

(c) F4y under 3.45 MPa vertical preload

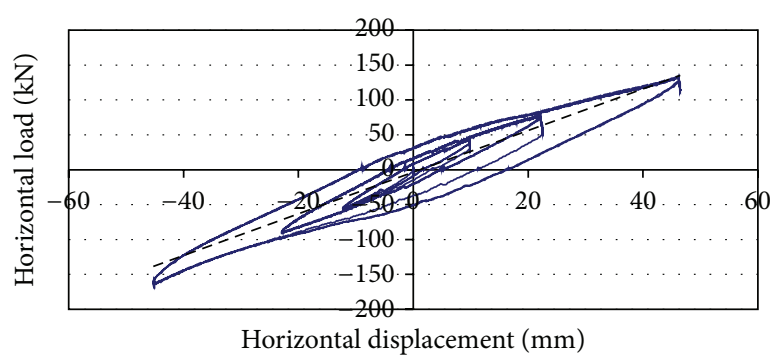

(b) $S 1 y$ under 6.90 MPa vertical preload

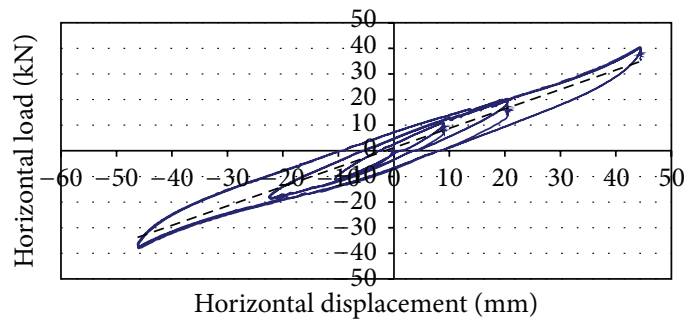

(d) $S 4 y$ under 3.45 MPa vertical preload

FIGURE 7: Horizontal shear test results for some of the specimens (horizontal load versus horizontal displacement for a pair of bearings).

\section{Conflict of Interests}

The authors declare that there is no conflict of interests regarding the publication of this paper.

\section{Acknowledgments}

The authors would like to thank the Middle East Technical University (BAP-03, 03, 2012, 003) and TUBITAK (KAMAG 110G093) for their financial support. Furthermore, the authors would like to acknowledge the Özdekan Kauçuk A. Ş. (Ankara, Turkey) and Maurer Söhne Group (Izmir, Turkey) for preparation and production of test specimens. The authors would also like to extend their thanks to General Directorate of Turkish Highways (KGM).

\section{References}

[1] J. M. Kelly, "Analysis of fiber-reinforced elastomeric isolators," Journal of Seismology and Earthquake Engineering, vol. 2, no. 1, pp. 19-34, 1999.

[2] B.-Y. Moon, G.-J. Kang, B.-S. Kang, and J. M. Kelly, "Design and manufacturing of fiber reinforced elastomeric isolator for seismic isolation," Journal of Materials Processing Technology, vol. 130-131, pp. 145-150, 2002.

[3] G. D. Ashkezari, A. A. Aghakouchak, and M. Kokabi, "Design, manufacturing and evaluation of the performance of steel like fiber reinforced elastomeric seismic isolators," Journal of Materials Processing Technology, vol. 197, no. 1-3, pp. 140-150, 2008.

[4] H. Toopchi-Nezhad, M. J. Tait, and R. G. Drysdale, "Lateral response evaluation of fiber-reinforced neoprene seismic isolators utilized in an unbonded application," Journal of Structural Engineering, vol. 134, no. 10, pp. 1627-1637, 2008.

[5] H. Toopchi-Nezhad, M. J. Tait, and R. G. Drysdale, "Shake table study on an ordinary low-rise building seismically isolated with SU-FREIs (stable unbonded-fiber reinforced elastomeric isolators)," Earthquake Engineering and Structural Dynamics, vol. 38, no. 11, pp. 1335-1357, 2009.

[6] H. Zhang, T. Peng, J. Li, and W. Li, "Experimental study of FRP rubber bearing," Advanced Materials Research, vol. 168-170, pp. 1621-1624, 2011.

[7] A. Calabrese and J. M. Kelly, "Mechanics of fiber reinforced bearings," PEER Report, University of California, Berkeley, Calif, USA, 2012.

[8] G. Russo, M. Pauletta, and A. Cortesia, "A study on experimental shear behavior of fiber-reinforced elastomeric isolators with various fiber layouts, elastomers and aging conditions," Engineering Structures, vol. 52, pp. 422-433, 2013.

[9] F. Hedayati Dezfuli and M. S. Alam, "Multi-criteria optimization and seismic performance assessment of carbon FRP-based elastomeric isolator," Engineering Structures, vol. 49, pp. 525540, 2013.

[10] A. Karimzadeh Naghshineh, U. Akyüz, and A. Caner, "Comparison of fundamental properties of new types of fibermesh-reinforced seismic isolators with conventional isolators," Earthquake Engineering and Structural Dynamics, vol. 43, no. 2, pp. 301-316, 2014.

[11] H. Toopchi-Nezhad, "Horizontal stiffness solutions for unbonded fiber reinforced elastomeric bearings," Structural Engineering and Mechanics, vol. 49, no. 3, pp. 395-410, 2014.

[12] J. M. Kelly and S. M. Takhirov, "Analytical and experimental study of fiber reinforced strip isolators," PEER Report, University of California, Berkeley, Calif, USA, 2002.

[13] G. Russo and M. Pauletta, "Sliding instability of fiber-reinforced elastomeric isolators in unbonded applications," Engineering Structures, vol. 48, pp. 70-80, 2013.

[14] S. Pinarbasi, U. Akyuz, and G. Ozdemir, "An experimental study on low temperature behavior of elastomeric bridge bearing," in Proceedings of the 10th World Conference on Seismic Isolation, Energy Dissipation and Active Vibrations Control of Structures, Istanbul, Turkey, May 2007. 
[15] C. Ozkaya, U. Akyuz, A. Caner, M. Dicleli, and S. Pinarbasi, "Development of a new rubber seismic isolator: 'Ball Rubber Bearing (BRB),' Earthquake Engineering and Structural Dynamics, vol. 40, no. 12, pp. 1337-1352, 2011.

[16] A. Caner, A. K. Naghshineh, and S. Erdal, "Performance of ball rubber bearings in low-temperature regions," Journal of Performance of Constructed Facilities, Article ID 04014060, 2013.

[17] AASHTO, Guide Specifications for Seismic Isolation Design, American Association of State Highway and Transportation Officials, Washington, DC, USA, 2nd edition, 2000.

[18] A. K. Chopra, Dynamics of Structures: Theory and Applications to Earthquake Engineering, Prentice Hall, Upper Saddle River, NJ, USA, 2nd edition, 2007.

[19] J. M. Kelly, "Buckling behaviour of elastomeric bearings," in Earthquake-Resistant Design with Rubber, Springer, London, UK, 2nd edition, 1997.

[20] M. Imbimbo and J. M. Kelly, "Stability aspects of elastomeric isolators," Earthquake Spectra, vol. 13, no. 3, pp. 431-449, 1997. 

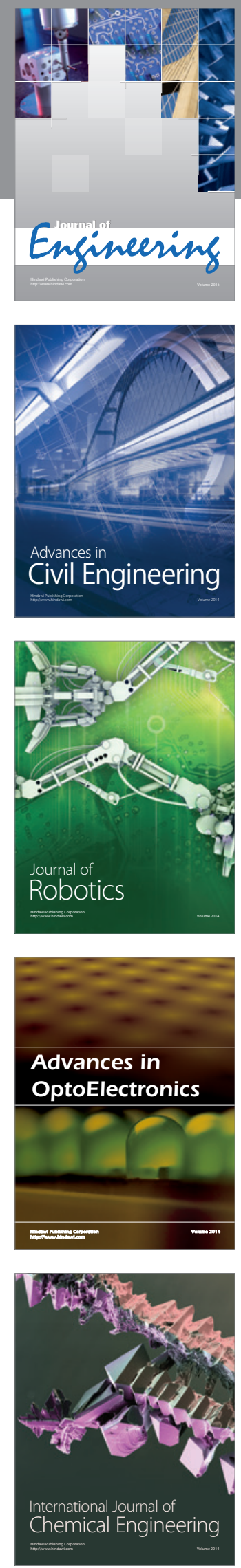

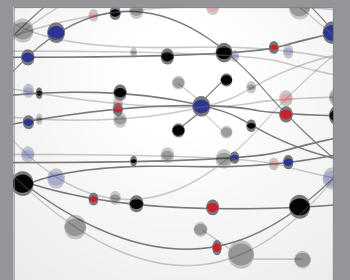

The Scientific World Journal
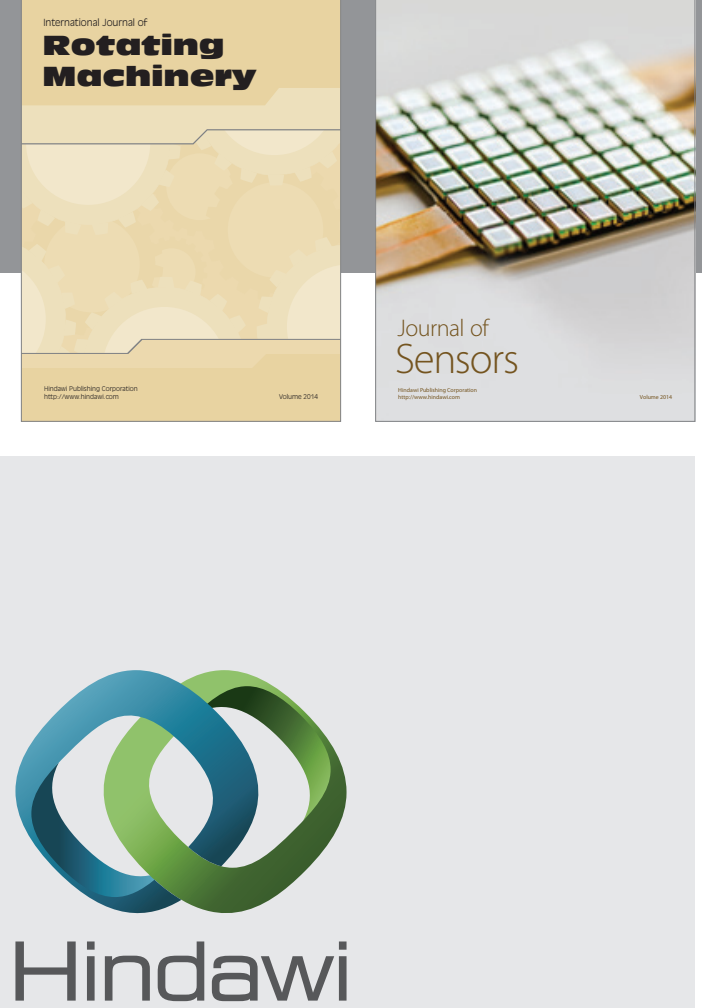

Submit your manuscripts at http://www.hindawi.com
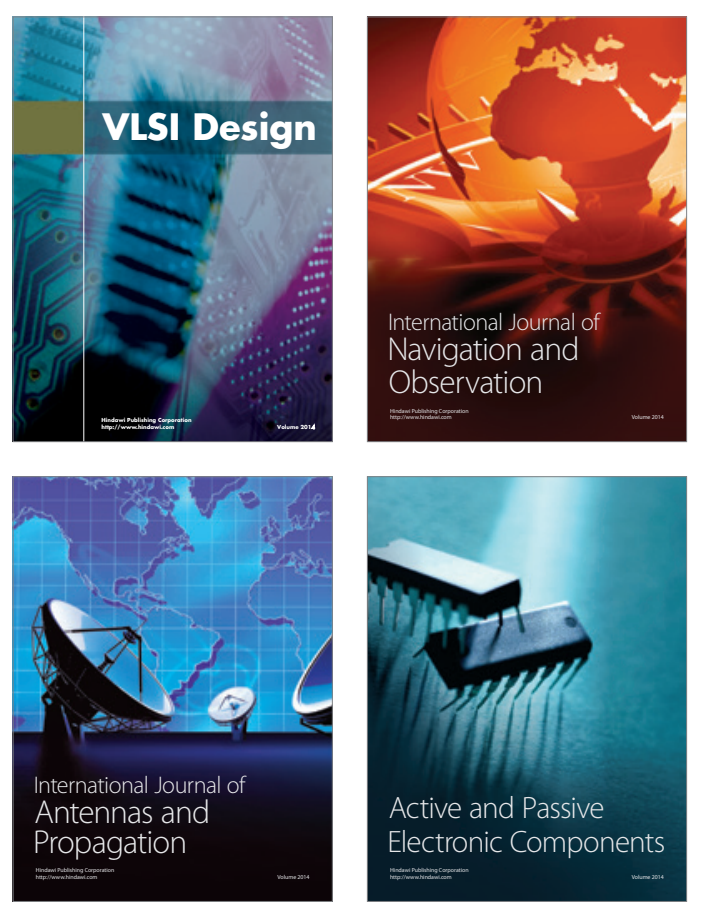
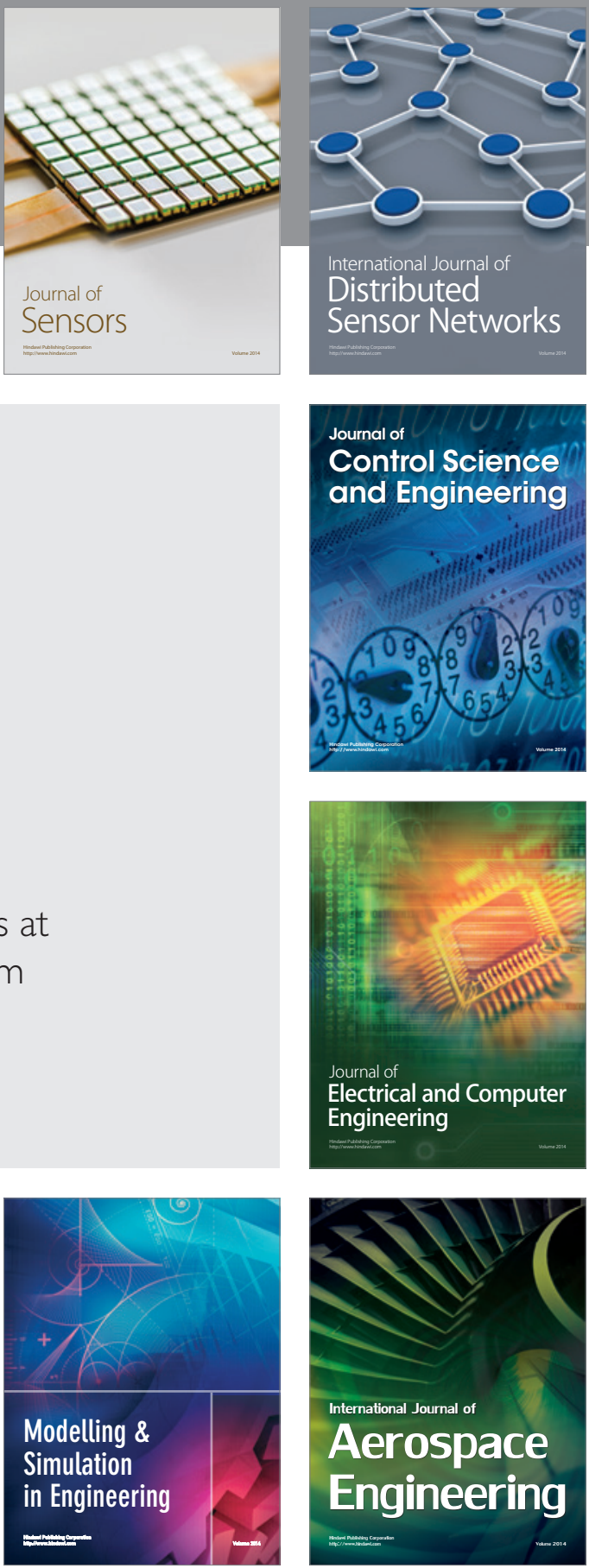

Journal of

Control Science

and Engineering
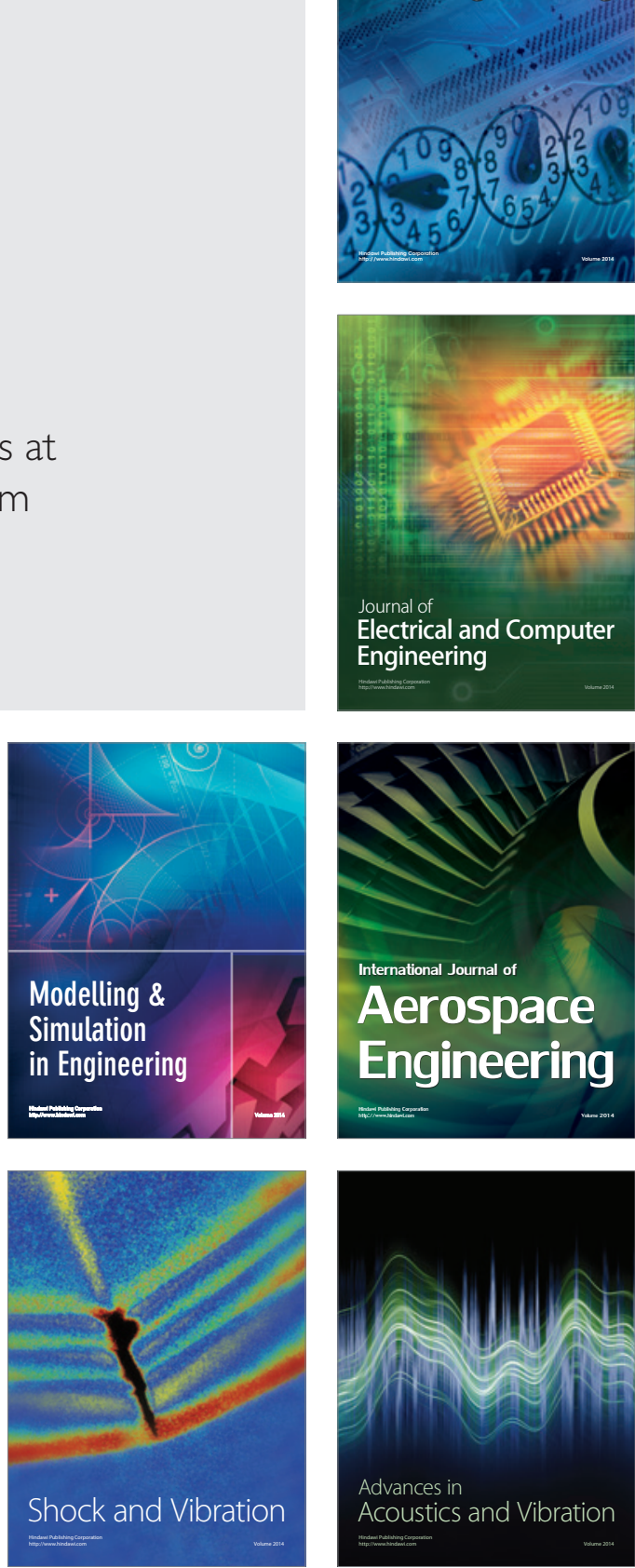